\title{
Neutron Chareacterization of BNCT Water Phantom Based on 30 MeV Cyclotron Using PHITS Computational Code
}

Okti Dyah Rahayuningsih ${ }^{1 *}$, Susilo ${ }^{2}$, Yohannes Sardjono ${ }^{1,2}$

${ }^{I}$ Department of Physics, Faculty of Mathematics and Siences, State University of Semarang, Semarang 50229, Indonesia

${ }^{2}$ Pusat Sains dan Teknologi Akselerator - Badan Tenaga Nuklir Nasional (PSTA-BATAN), Yogyakarta 55281, Indonesia

\section{ARTICLE INFO}

Article history:

Received: 25 August 2018

Received in revised form: 30 October 2018

Accepted: 20 January 2019

\section{Keywords:}

Keyword cancer Keyword BNCT Keyword neutron Keyword characterization Keyword cyclotron Keyword PHITS

\begin{abstract}
A B S T R A C T
Cancer is the second leading cause of death globally and was responsible for 8,8 million deaths in 2015. Approximately $70 \%$ of deaths from cancer occur in low- and middle-income countries. The war on cancer has been fought with three tools - surgery (cut), radiation therapy (burn) including radiotherapy and bracytherapy, and also chemotherapy (poison). Cancer therapy has increased life expectancy of patients but each treatment modality has its own effects, complications and toxicity. Moreover we have found a new effective method to fight cancer, that is, Boron Neutron Capture Therapy (BNCT). Boron Neutron Capture Therapy (BNCT) has for many decades been advocated as an innovative form of radiotherapy that, in principle, has the potential to be the ideal form of treatment for many types of cancers. This research's aim is the characterising neutron of BNCT water phantom based on 30 $\mathrm{MeV}$ cyclotron using PHITS computational code. The result from the simulation is that thickness of the water phantom, related to flux neutron.
\end{abstract}

(C) 2019 IJPNA. All rights reserved.

\section{INTRODUCTION}

Cancer is the second leading cause of death globally and was responsible for 8,8 million deaths in 2015. Globally, nearly 1 in 6 deaths is due to cancer. Not only it in the same year cancer also be a leading causes of death worldwide. Approximately $70 \%$ of deaths from cancer occur in low and middle-income countries. The most common causes of cancer death are cancers of the lung (1.69 million deaths), liver (788 000 deaths), colorectal (774 000 deaths), stomach (754 000 deaths) and breast (571 000 deaths).[1] Meanwhile 14.1 million new cancer cases and 8.2 million cancer deaths occured in 2012 worldwide, with the most common cancer death from lung cancer (1.6 million deaths), liver cancer (745 000 deaths), stomach cancer (723000 deaths), colorectal cancer (693 000 deaths), and breast cancer (522 000 deaths).[2]

*E-mail: dyahokti@gmail.com
The data shows that there had been increased cancer causes in the world. Although Indonesia is not included in the 50 biggest countries whith the highest cancer death rate, but in 2012 Indonesia had high enough cancer deaths for 1.551 million of the total Indonesian population of 247 million. [3] The prevalence of Indonesian cancer causes was 1,4 \%o, with the highest prevalence in DI Yogyakarta $(4,1$ \%o), following Central Java (2,1\%), Bali (2 \%o), Bengkulu and DKI Jakarta at 1,9\%o. [4]

Cancer is a group of diseases characterized by the uncontrolled growth and speread of abnormal cells. If the spread is not controlled, it can result in death. [5] But there is no type of cancer from which some people have not recovered. The road to recovery generally is not very easy and requires real determination.[6]

The war on cancer has been fought with three tools - surgery (cut), radiation therapy (burn) including radiotherapy and bracytherapy, and also chemotherapy 
Volume 4, Number 1, February 2019, p. 22-27 e-ISSN 2550-0570, C FSM UKSW Publication

(poison).[7] Cancer therapy has increased life expectancy of patients but Each treatment modality has its own effects, complications and toxicity ; [8] such as cardiac toxicity following radiotherapy that can manifest itself as arrhythmias, pericarditis, congestive heart disease, ischemic heart disease (myocardial infarctions), or valvular disease with the pathogenesis of these entities suggested to be fibrosis/damage of the AV node and conduction system, inflammation, fibrosis, accelerated atherosclerosis, and fibrosis respectively.[9] In collon cancer operations can cause difficult lymphatic to drainage after surgery [10] and laryngectomy is often required, which inevitably results in permanent tracheostomy and loss of the natural voice. [11] Furthermore, some cancer therapy can change be a more chronic disease. For example a benign tumor can be malignant. Moreover a new effective method to fight cancer, that is, Boron Neutron Capture Therapy (BNCT). [12] Boron Neutron Capture Therapy (BNCT) has for many decades been advocated as an innovative form of radiotherapy that, in principle, has the potential to be the ideal form of treatment for many types of cancers.[13]

\subsection{Boron Neutron Capture Therapy (BNCT)}

Boron neutron capture therapy (BNCT) is an emerging cancer treatment modality that utilizes the neutron capture reaction of boron10 (10B) and subsequent nuclear fission reaction to produce cellular death. [14] The result of this reaction is $10 \mathrm{~B}(n, \alpha) 7 \mathrm{Li}$ which has high LET ( Linier Energy Transfer) with $\alpha$ particle $150 \mathrm{keV} \mu \mathrm{m}-1$ and the $7 \mathrm{Li} 175$ $\mathrm{keV} \mu \mathrm{m}-1$. [17][18]

Dosimetry of BNCT is very complicated because of the presence of different dose components including oron dose (DB): The dose from $10 \mathrm{~B}(\mathrm{n}, \alpha) 7 \mathrm{Li}$ reaction; gamma dose $(\mathrm{Dg})$ : The dose from the neutron beam and $1 \mathrm{H}(\mathrm{nth}, \gamma) 2 \mathrm{H}$ reaction; thermal neutron dose (Dth): The dose resulting from thermal neutron capture in nitrogen $14 \mathrm{~N}(\mathrm{nth}, \mathrm{p}) 14 \mathrm{C}$; fast neutron dose (Df): The dose from the $1 \mathrm{H}(\mathrm{n}$, n') $2 \mathrm{H}$ reaction.[15] Besides the dose delivered to the target organ in a BNCT treatment, the doses deposited in the remaining organs may induce secondary cancer risk.[16] Moreover, we have to calculate more about the neutron fluks. Because of calculation of the fluks we have to make a simulation using Particle and Heavy Ion Transport Code System (PHITS).

\subsection{Cyclotron- Based Neutron Source}

In 2006 KURRI and SHI started development of the accelerator based neutron source for BNCT. In order to get high flux of epithermal neutrons, a combination of $30 \mathrm{MeV}$ proton beams and a beryllium target was selected after the feasibility study. The neutron source consists of a cyclotron as the accelerator, a beam transport system and an irradiation and treatment system. Figure 1 shows the layout of the neutron source. The source was installed in December 2008 at the Innovation Research Laboratory in KURRI. The main equipments were installed in the area of $18 \mathrm{~m}$ long and $15 \mathrm{~m}$ wide excluding power supply rooms.[19]

This KURRI project has to deal with a very hard neutron spectrum. The current status have target beam energi $30 \mathrm{MeV}$, beam current $1 \mathrm{~mA} .[20]$

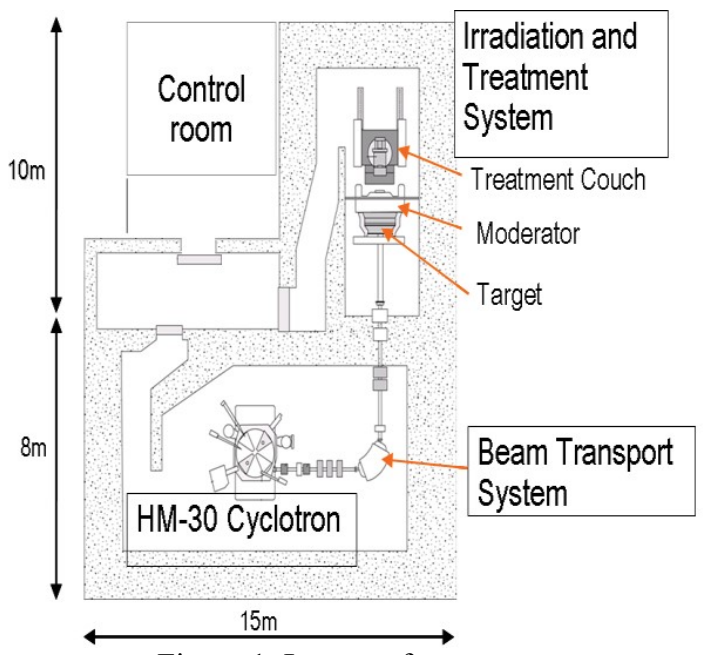

Figure 1. Layout of neutron source.

\subsection{Particle Heavy Ion Transport System (PHITS)}

PHITS have been used for several medicine aplications such as radiation dose therapy estimation and tomograph investigation computer based. Several reasons for using 
PHITS is that it has high acuration, less computation time, less suspending file, repairing fault in MCNPX, detail investigation, can simulate all the kinds of particle transport and is used in various calculating microdosimetri applications; such as bilogy dose estimation from the multiplication betwen RBE and phisycs dose.[21][22][23]

\section{MATERIALS AND METHODS}

\section{Legal Requirement}

The designing to know the neutron characterization of water phantom BNCT based on $30 \mathrm{MeV}$ cyclotron have been done using a set of programs PHITS.

The procedure of the reasearch implementation is formulated in a flow chart shown by figure 2 .

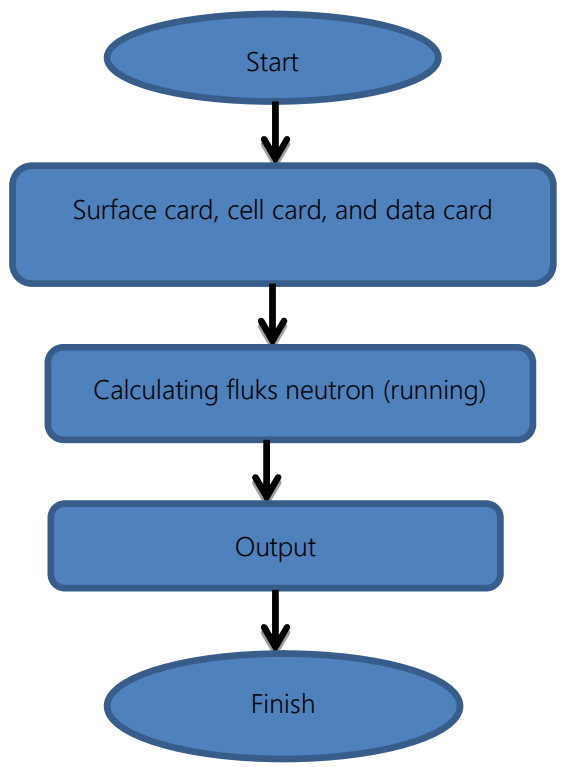

Fig 2. Fluks calculation algorithm on PHITS programs.

TABLE 1. Main specification of HM-30 cyclotron.

\begin{tabular}{lc}
\hline Accelerated Particle & Negative hydrogen ion \\
Extraction Energy & $30 \mathrm{MeV}$ \\
Extraction Method & Foil stripping \\
Maximum Beam Current & $2 \mathrm{~mA}$ \\
Nominal Operation Current & $1 \mathrm{~mA}$ \\
Magnet Size & $3.0 \mathrm{mx} 1.6 \mathrm{~m} \mathrm{x} 1.7 \mathrm{~m}$ \\
Weight & 60 tons \\
\hline
\end{tabular}

This reaserch's main specification using cyclotron $30 \mathrm{MeV}$ based is shown on table 1 .

\section{RESULTS AND DISCUSSION}

Neutron characterization has been designed using PHITS. HM-30 cyclotron succesfully accelerated the $30 \mathrm{MeV}$ proton beam which is limited by the radiation regulation of the building. The cyclotron is stable.

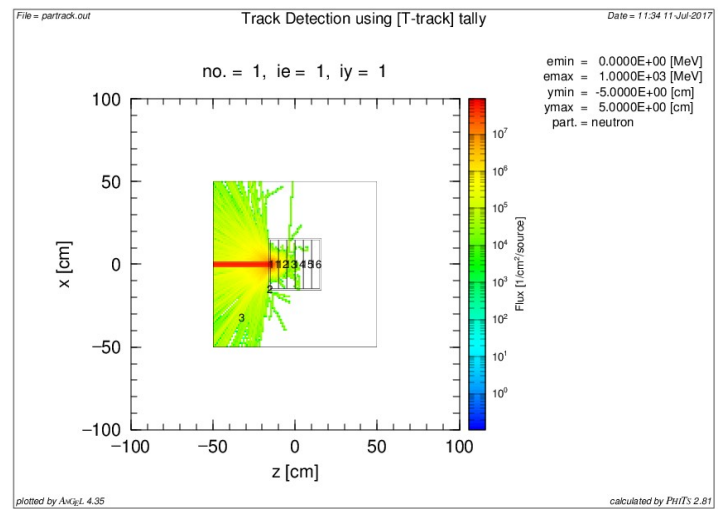
PHITS.

Fig 3. The design neutron characterization using

The water phantom was positioned in $\mathrm{y}$ axis from $-5.000 \mathrm{~cm}$ to $5.000 \mathrm{~cm}$ and the energy from $0.000 \mathrm{MeV}$ to $1.000 \mathrm{MeV}$.

Results after the program had been running are shown in figure 4,5,6,7,8,and 9 .

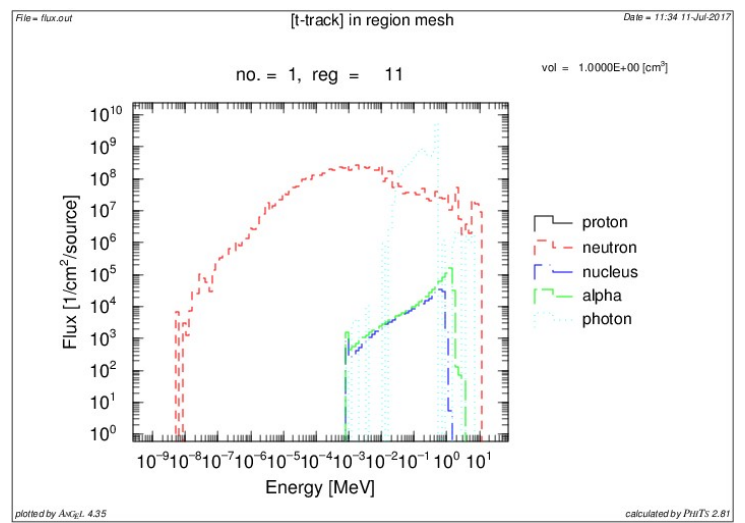

Fig 4. Fluks characterization in region 1.

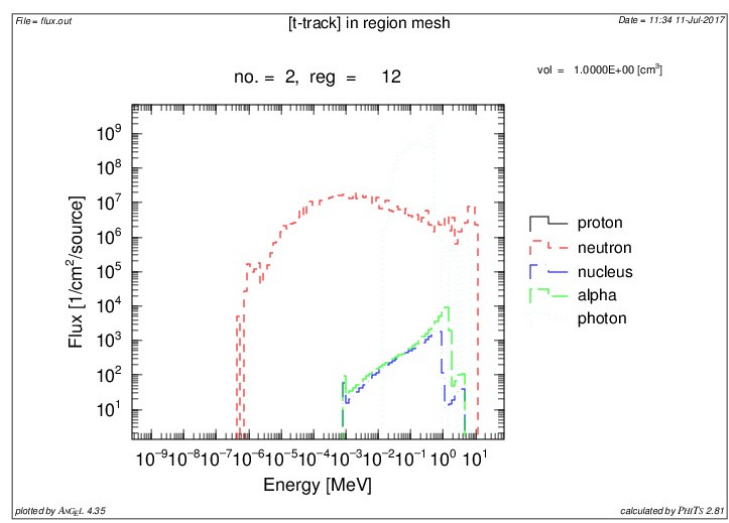


Fig 5. Fluks characterization in region 2.

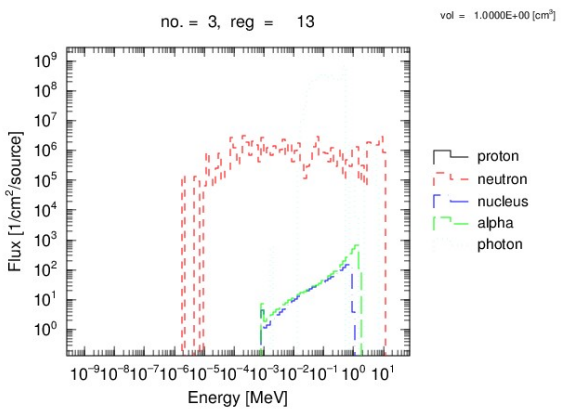

Fig 6. Fluks characterization in region 3.

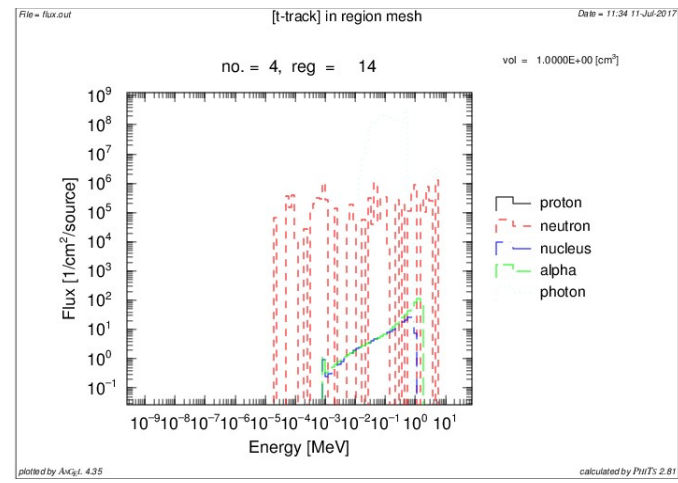

Fig 7. Fluks characterization in region 4.

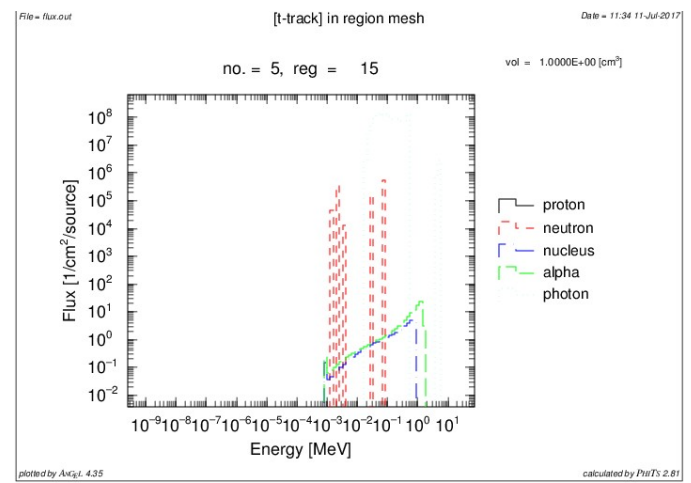

Fig 8. Fluks characterization in region 5.

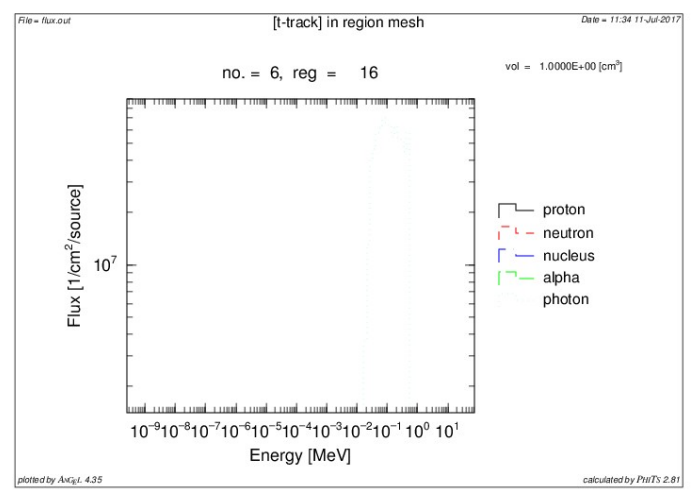

Fig 9. Fluks characterization in region 6.

\section{CONCLUSION AND REMARKS}

The result from the simulation is that the ticker of water phantom has smaller neutron flux.

\section{ACKNOWLEDGMENT}

Acknowledgment for Pusat Sains dan Teknologi Akselerator - Badan Tenaga Nuklir Nasional (PSTA-BATAN), Yogyakarta 55281, Indonesia.

\section{REFERENCES}

[1] WHO. 2017. Available from:http://www.who.int/mediacentre/factsheet s/fs297/en/, accessed on 16/02/2017

[2] Cancer incidence and mortality worldwide: sources, methods and major patterns in GLOBOCAN 2012 1J. Ferlay, 1I. Soerjomataram I, 2R. Dikshit, 3S. Eser, 4C. Mathers, 5M. Rebelo, 6D.M. Parkin, 1D. Forman D, 1F. Bray.. international journal of cancer page 1-79, 2015 Mar 1;136(5):E359-86. doi: 10.1002/ijc.29210. Epub 2014 Oct 9

[3] WHO.2014.Cancer Country Profiles

[4] Badan Penelitian Dan Penegembangan Kesehatan Kememnterian Kesehatan RI. 2013.Riset Kesehatran Dasar. Jakarta. Kementerian Kesehatan RI

[5] American Cancer Society. 2017. Cancer Fact and Figures 2017. Atlanta,Georgia. American Cancer Society

[6] Annette and Richard Bloch. 1988. Fighting Cancer. Missouri. R.A. Bloch Cancer Foundation

[7] Michael Lam. 2003. Beating Cancer with Natural Medicine. United States of America. Bloomington, IN

[8] Johanes M. Huitink and Wendy H.L. 2013. Current cancer therapies- Aguide for perioperative physicians. Best Practice \& Research Anaesthesiology 2013;27:481-492.

[9] Chirag Shah, Shahed Badiyan, Sameer Berry, Atif J. Khan, Sharagd Goyal, Kevin Schulte, Anish Nanavati, Melanie Lynch, Frank A. Vicini. 2014. Cardiac dose sparing and avoidance techniques in breast cancer radiotherapy. Radiotherapy and Oncology 2014 
[10] Sukamal Saha, Gregory Johnston, Alpesh Korant, Mohammed Shaik, Mohammed Kanaan, Rebecca Johnston, Balvant Ganatra, Sunil Kaushal, Dilip Desai, Sreenivas Mannam. 2013. Aberrant drainage of sentinel lymph nodes in colon and its impact on staging and extent of operation. The American Journal of Surgery 2013; 205: 302-306.

[11] Aaro Haapaniemi, Leena Kankaanranta, Riset Saat, Hanna Koivonuro, Kauko Saarilahti, Antii Makitie, Timo Atula, Heikki Joensuu. 2015. Boron Neutron Capture Therapy in the Treatment of Recurrent Laryngeal Cancer. International Journal of Radiation Oncology Biology Physic 2015 ; :1-7

[12] Aaro haapaniemi, Leena Kankaanranta, Riset Saat, Hanna Koivonuro, Kauko Saarilahti, Antii Makitie, Timo Atula, Heikki Joensuu. 2015. Boron Neutron Capture Therapy in the Treatment of Recurrent Laryngeal Cancer. International Journal of Radiation Oncology Biology Physic $2015 ;: 1-7$

[13] Raymond L. Moss. 2013. Critical review, with an optimistic outlook, on Boron Neutron Capture Therapy (BNCT). Applied Radiation and Isotopes 2013; 88: 2-11.

[14] Micah John Luderer, Pilar de la Puente, Abdel Kareem Azab. 2015. Advancement in Tumor Targeting Strategies for Boron Neutron Capture Therapy. Springer Pharm Res

[15]Elham Bavarnegin, Alireza Sadremomtaz, Hossein Khalafi, Yaser Kasesaz. 2016. Measurement of in-phantom neutron flux and gamma dose in Tehran research reactor boron neutron capture therapy beam line. Journal of Research and Therapeutics 2016;12:826-9

[16] ] Jeng-Ning Wang, Kuo-Wei Lee, Shiang-Huei Jiang. 2013. Effective dose evaluation for BNCT brain tumor treatment based on voxel phantoms. Applied Radiation and Isotopesm 2013;12:012

[17] M.Monshizadeh, Y. Kasesaz, H. Khalafi, S. Hamidi. 2015. MNCP design of thermal and epithermal neutron beam for BNCT at the Isfahan MNSR. Progress in Nuclear Energy 2015; 83 :427-732.

[18] Wolfgang A.G Saurwein. 2012. Principle and Roots of Neutron Capture Therapy. Neuton Capture Therapy Principle and Applications Springer $2012 ;: 1-18$

[20] Accelerator-basedBNCT A.J.Kreiner a,b,c,n, M.Baldo a, J.R.Bergueiro a,c, D.Cartelli a,b,c, W.Castell a, V.ThatarVento b, J. GomezAsoia a, D.Mercuri a, J.Padulo a, J.C.SuarezSandin a, J.Erhardt a, J.M.Kesque a, A.A.Valda a,b, M.E.Debray a,b, H.R.Somacal a,b, M.Igarzabal a, D.M.Minsky a,b,c, M.S. Herrera a,b,c, M.E.Capoulat a,b,c, S.J.Gonzalez a,c, M.F.delGrosso a,c, L.Gagetti a,b,c, M. SuarezAnzorena a, M.Gun d, O.Carranza a

[19] Cyclotron-based neutron source for BNCT

T. Mitsumoto, S. Yajima, H. Tsutsui, T. Ogasawara, K. Fujita et al.

[21] Tatsuki Sato, Koji Niita, Norihiro Matsuda, Shintaro Hashimoto, Yosuke Iwamoto, Shusaku Noda, Hiroshi Iwase, Hiroshi Nakashima, Tokio Fukahori, Satoshi Chiba, and Lembit Sihver. 2014. Overview of the PHITS code and its application to medical physics. Progress in Nuclear Science and Technologi $2014 ; 4: 879-882$

[22] Hironuori Horiguchi, Tatsuko Sato, Hiroaki Kumada, Tetsuya Yamamoto and Takeji Sakae. 2014. Estimation of relative biological effectiveness for neutron capture therapy sing the PHITS code coupled with a microdosimetric kinetic model.Journal of Radiation Research 2014:1-9

[23] Tatsuki Sato, Koji Nitta, Norihiro Matsuda, Shintaro Hashimoto, Yosuke Iwamoto, Shusaku Noda, Tatsuhiko Ogawa, Hiroshi Iwase, Hiroshi Nakashima, Tokio Fukahori, Keisuke Okumura, Tetsuya Kai, Satoshi Chiba, Takuya Furuta, Lembit Sihver. 2013. Particle and Heavi Ion Transport code System, PHITS, version 2.52. Journal of Nuclear Science and Technology 2013; 50: 913-923. 